\title{
ANÁLISE DAS SEQUÊNCIAS ARGUMENTATIVAS PROTOTÍPICAS PRODUZIDAS POR ALUNOS DO ENSINO MÉDIO
}

\author{
Eleone Ferraz de Assis (UEG) \\ Fernanda Martins da Costa Gomes (UEG)
}

Resumo: Este artigo apresenta uma análise das sequências textuais prototípicas dos gêneros argumentativos produzidos pelos alunos do 3 ano do Ensino Médio na disciplina de Língua Portuguesa. Verifica-se como as sequências argumentativas prototípicas estão organizadas nos textos dos alunos que estão concluindo a educação básica. Para tanto, o estudo fundamenta-se nos apontamentos teóricos de Bakhtin (2010 [1992]), Adam (2005, 2008), Bezerra (2009), Marcuschi (2002, 2008), Rojo (2005), Motta-Roth (MOTTA-ROTH; HEBERLE, 2005), Bonini (2005), Brait (2000), Rodrigues (2005), PCN (BRASIL, 2000) e PCN+ (BRASIL, 2002). Em uma investigação mais ampla, em curso, propõe-se analisar os gêneros textuais e descrever as sequências textuais argumentativas prototípicas, com o intuito de preencher lacunas existentes, sobretudo no estudo dos gêneros textuais argumentativos, e apontar caminhos teórico-metodológicos para o ensino de produção textual.

Palavras-chave: Língua Portuguesa; Produção Textual; Sequências Argumentativas Prototípicas; Educação Básica.

Abstract: This article analysis the prototypical textual sequences in argumentative genre produced by high school graduating students in the Portuguese subject. This study investigated how the prototypical argumentative sequences are organized in the text of the students who are graduating from basic education. For doing so, the student has theoretical support from: Bakhtin (1992-2010), Adam (2005-2008), Bezerra (2009), Marcuschi (2002-2008), Rojo (2005), Motta-Roth (2005), Bonini (2005), Brait (2000), Rodrigues (2005), PCN (2000) and PCN+ (2002). The investigation intends to analyze the textual genre and describe the prototypical argumentative sequences with the intention of filling the existing spaces, specially, in argumentative textual genre study and showing theoretical-methodological path to teaching textual production.

Keywords: Portuguese; Textual Production; Prototypical Argumentative Sequence; Basic Education. 


\section{INTRODUÇÃO}

Esta pesquisa investiga a produção dos gêneros argumentativos no $3^{\circ}$ ano de Ensino Médio de uma escola da rede pública da cidade de Goiás. A análise incide sobre as sequências argumentativas prototípicas, para verificar como elas se organizam nos textos dos alunos que estão concluindo a educação básica. Para tanto, desenvolve-se uma pesquisa qualitativa, buscando destacar os apontamentos de sequências textuais (ADAM, 2008).

Ao analisar os gêneros textuais e descrever as sequências textuais argumentativas prototípicas, o intuito é preencher lacunas existentes, sobretudo no estudo dos gêneros textuais argumentativos e assim, apontar caminhos teóricometodológicos para o ensino de produção textual.

A hipótese evidenciada pela leitura dos aportes teóricos recai na compreensão de que os gêneros textuais são "textos materializados em situações comunicativas recorrentes [...] que encontramos em nossa vida diária e que apresentam padrões sociocomunicativos característicos definidos por composições funcionais, objetivos enunciativos e estilos" (MARCUSCHI, 2008, p.155). Os gêneros argumentativos, nessa perspectiva, dizem respeito aos textos que discutem problemas controversos, buscando a sustentação de uma opinião ou sua refutação, tomando uma posição. 
Para tanto, a investigação fundamenta-se, sobretudo, em Bakhtin (1992), Brait (2000), Marcuschi (2002, 2008), Rojo (2005), Motta-Roth (MOTTA-ROTH; HEBERLE, 2005), Bonini (2005), Rodrigues (2005), PCN (BRASIL, 2000), PCN+ (BRASIL, 2002) e Adam (2008).

Para examinar como os alunos organizam as sequências argumentativas prototípicas, este artigo apresenta, como aporte teórico-metodológico, uma análise de textos argumentativos produzidos por eles.

\section{APORTE TEÓRICO}

\subsection{Os gêneros textuais}

O filósofo russo Bakhtin (1992) é quem mais influenciou e influencia os pesquisadores que trabalham com a teoria dos gêneros. Assim ele defende:

O emprego da língua efetua-se em forma de enunciados (orais e escritos), concretos e únicos, proferidos pelos integrantes desse ou daquele campo da atividade humana. Esses enunciados refletem as condições específicas e as finalidades de cada referido campo não só por seu conteúdo (temático) e pelo estilo da linguagem, ou seja, pela seleção dos recursos lexicais, fraseológicos e gramaticais da língua, mas, acima de tudo, por sua construção composicional. Todos esses três elementos - o conteúdo temático, o estilo, a construção composicional estão indissoluvelmente ligados no todo do 
enunciado e são igualmente determinados pela especificidade de um determinado campo da comunicação. Evidentemente, cada enunciado particular é individual, mas cada campo de utilização da língua elabora seus tipos relativamente estáveis de enunciados, os quais denominamos gêneros. (2010 [1992], p.261-262)

Por conseguinte, a formação dos gêneros está interligada com a situação social de interação verbal dentro de um determinado campo social, não com suas propriedades formais. Acerca disso refere Rodrigues (2005, p.164-165):

Cada esfera, com sua função socioideológica particular (estética, educacional, jurídica, religiosa, cotidiana etc.) e suas condições concretas específicas (organização socioeconômica, relações sociais entre os participantes da interação, desenvolvimento tecnológico etc.), historicamente formula na/ para a interação verbal gêneros discursivos que the são próprios. Os gêneros se constituem e se estabilizam historicamente a partir de novas situações de interação verbal (ou outro material semiótico) da vida social que vão se estabilizando, no interior dessas esferas.

Durante muito tempo, os gêneros foram vistos em grande parte apenas pelo ângulo artístico-literário, “[...] e não como determinados tipos de enunciados que são diferentes de outros tipos, mas têm com estes uma natureza verbal (linguística) comum" (BAKHTIN, 2010 [1992], p.262-263). 
Rodrigues assinala:

Cada gênero está assentado em um diferente cronotopo, pois inclui um horizonte espacial e temporal (qual esfera social, em que momento histórico, qual situação de interação), um horizonte temático e axiológico (qual o tema do gênero, qual a sua finalidade ideológico-discursiva) e uma concepção de autor e destinatário. (2005, p.165)

Nessa perspectiva, a língua se efetiva em forma de enunciados (quer sejam orais ou escritos) que os integrantes de uma esfera da atividade humana utilizam. O enunciado é a unidade real da comunicação verbal, ele nunca se repete, é um evento único, individual, apresenta características estruturais que lhe são comuns e possui fronteiras delimitadas que são determinadas pela alternância dos sujeitos falantes. $O$ discurso só se concretiza por meio de enunciados (BAKHTIN, 2010 [1992]).

Cada esfera de comunicação apresenta especificidades que lhe são inerentes e que marcam no enunciado três elementos que se fundem indissoluvelmente: a) conteúdo temático: é o objeto do discurso que é dizível por meio do gênero; b) estilo: consiste na seleção de recursos gramaticais, léxicos, fraseológicos; c) construção composicional: textos pertencentes a um gênero compartilham de determinados procedimentos composicionais em sua estrutura (ROJO, 2005). 
A situação de produção dos enunciados e a apreciação valorativa do locutor sobre o tema e de seus interlocutores determinam essas especificidades no enunciado, o qual se caracteriza como unidade real e concreta da comunicação discursiva.

Influenciados pela discussão de gênero realizada por Bakhtin, muitos teóricos, preocupados (ou não) com o ensino de língua, tomam as sequências textuais como base para o desenvolvimento de estudos voltados para a produção de texto. É o caso de Adam (2008), para quem os gêneros são compreendidos como componentes da interação social, materializados por meio de sequências textuais.

\subsection{As sequências textuais nos gêneros}

Para Adam (2001), o texto é complexo e heterogêneo. É composto de sequências que, sob determinados aspectos, são independentes, ou seja, cada sequência, em si mesma, possui traços característicos que a individualizam; contudo, são dependentes sob outros aspectos, pois não existem à revelia dos gêneros textuais. Sob esse ângulo, as sequências textuais não são autônomas. Enquanto os gêneros textuais englobam um número maior de ocorrências no meio social, as sequências aparecem de forma mais simplificada e em um mesmo gênero podem-se encontrar várias sequências. 
Adam (2008, p. 122) assim define sequência textual:

[...] uma ESTRUTURA, quer dizer como:

- uma rede relacional hierárquica: grandeza decomponível em partes ligadas entre si e ligadas ao todo que elas constituem;

- uma entidade relativamente autônoma, dotada de uma organização interna que Ihe é própria e, portanto, em relação de dependência/independência com o conjunto mais amplo de que ela faz parte.

Levando em conta a relativa estabilidade dos enunciados de Bakthin (2010 [1992]), Adam (2001) propôs uma reflexão enfocando as características formais e enunciativas dos textos, definidas como sequências textuais. Como em tal consideração, ele propõe cinco tipos de sequências textuais que podem ser encontradas nos gêneros: narrativa, descritiva, argumentativa, explicativa e dialogal.

A sequência narrativa, segundo Adam (2001), pode ser caracterizada pela sucessão de eventos, que são organizados por processos e têm um tema. A narrativa tem começo, meio e fim, sendo assim, apresenta referências de tempo/espaço.

Em relaçãoà sequência descritiva, Adam (2001) ressalta que ela se constitui de três partes: ancoragem, estabelecimento de relações entre entidades e percepção global do tema. Pode-se afirmar que a descrição está bastante relacionada à narrativa e, por isso, raras vezes, será encontrada como 
marca predominante de um texto. Geralmente, a descrição aparece na narrativa, sobretudo na parte inicial (a situação) desta, quando são apresentados o espaço e os personagens.

A sequência explicativa, de acordo com Adam (2001), tem o intuito de mostrar uma ideia, apontar um estado de conhecimento, mas sem convencer como um argumento. Já a sequência dialogal tem a função de demonstrar a troca verbal entre os falantes. Sendo assim, é formada por mais de um interlocutor e apresenta marcas linguísticas relacionadas à interlocução.

A sequência argumentativa, por sua vez, tem a função de persuadir e convencer o interlocutor na interação verbal. $\mathrm{O}$ ato argumentativo consiste na oposição de enunciados, os quais são interligados por operadores argumentativos. Tem por princípio a ideia de que uma argumentação consiste em dois movimentos: na demonstração de uma tese e na refutação dessa tese.

Nos gráficos que seguem, busca-se ampliar e retomar o esquema de base que Adam (2001) denomina de sequência argumentativa prototípica. 


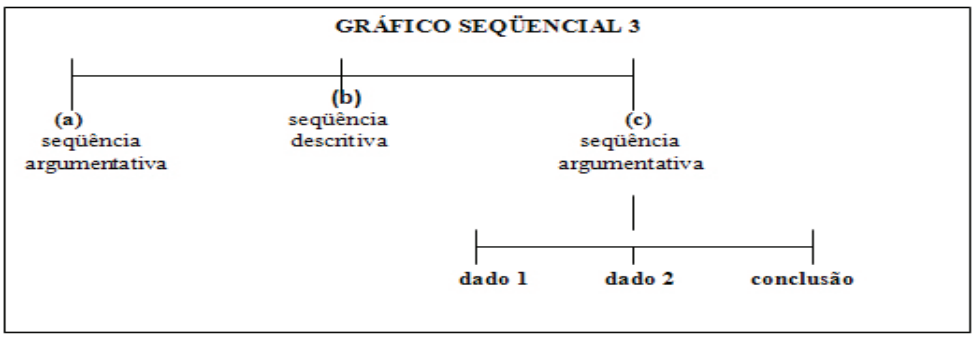

Figura 1 - Gráfico sequencial. Fonte: ADAM (2001, p.234)

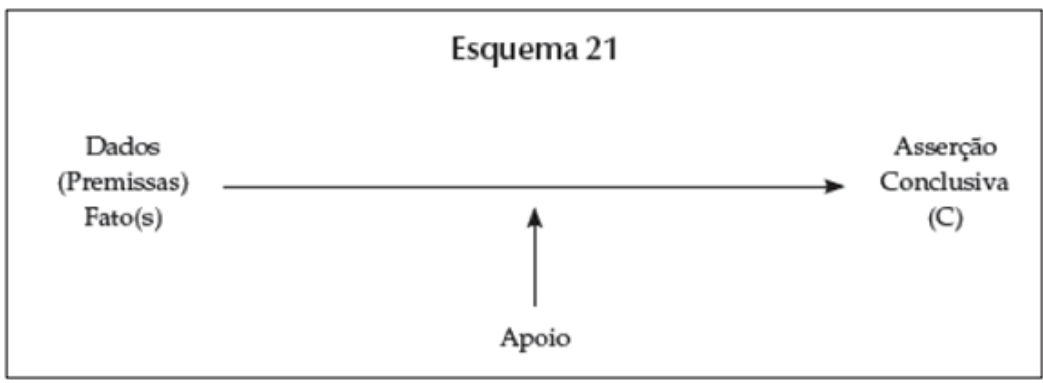

Esquema 1. (Adam 2011: 233)

Figura 2 - Esquema simplificado de uma sequência argumentativa de Adam (2001). Fonte: ADAM (2001, p.233)

Segundo Adam (2008), a sequência argumentativa concretiza-se por meio de dois movimentos - a demonstração e/ou justificativa de uma tese e a refutação de outras teses ou argumentos - e a partir de premissas estabelecidas, chegase a uma conclusão ou afirmação. Em outras palavras, nesse tipo de sequência apresenta-se uma posição favorável ou desfavorável no que diz respeito a uma tese inicial e sustentase uma posição com base em argumentos ou provas. 


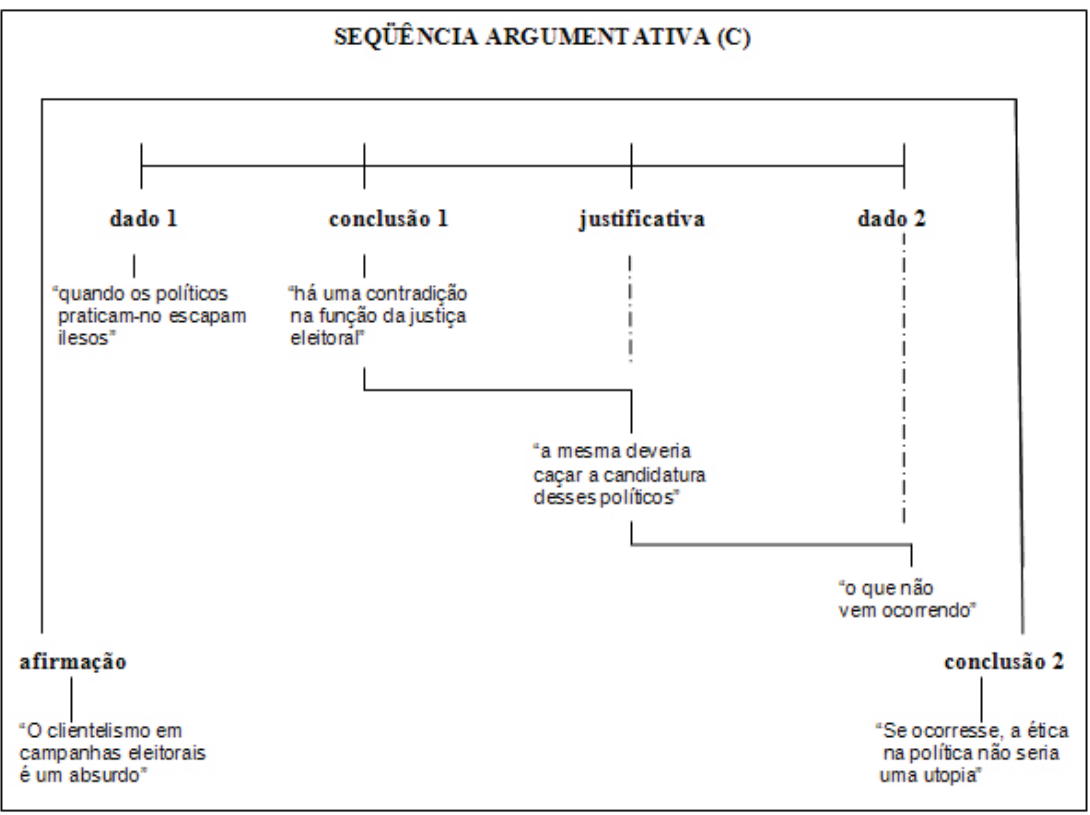

Figura 3 - Sequência argumentativa. Fonte: ADAM (2001, p.233)

Identificadas por P.arg (proposição argumentativa), as seguintes macroposições dão base ao esquema: os dados (P. arg1), as inferências (P. arg2) e a conclusão (P.arg3), as quais estão relacionadas a uma tese anterior (P. $\arg 0)$, uma afirmação a ser refutada. É interessante observar que essa tese anterior não precisa estar explícita no texto, nem as inferências, posto que são determinadas pelo sentido do enunciado. Os dados (afirmações) levam, por intermédio de operadores de conclusão ou restrição (P.arg4), a uma conclusão (opinião do enunciador), que pode servir de base a uma nova sequência argumentativa. 
Figura 4 - Protótipo da sequência argumentativa:

\begin{tabular}{|c|c|c|c|c|}
\hline \multicolumn{5}{|c|}{ SEQUÊNCIA ARGUUMEIT TATIYA } \\
\hline $\begin{array}{l}\text { TESE + } \\
\text { Antarior } \\
\text { P. arg 0 }\end{array}$ & $\begin{array}{l}\text { DADOS } \\
\text { (Premiasos) } \\
\text { P. arg l }\end{array}$ & $\begin{array}{l}\text { Ancorage th } \\
\text { dae inferências } \\
\text { P. arg } 2\end{array}$ & $\begin{array}{l}\text { portanto provavelmente } \\
\text { a menos qus } \\
\text { RESTPIÇA } \\
\text { P.arg } 4\end{array}$ & $\begin{array}{l}\text { CONCLUSÄO } \\
\text { (Nora) T日8e } \\
\text { P.arg } \mathbf{3}\end{array}$ \\
\hline
\end{tabular}

Fonte: Adam (1992, p. 118)

Figura 3-Plano de organização da textualidade:

\begin{tabular}{|c|c|c|}
\hline \multicolumn{3}{|c|}{ TEXTO } \\
\hline & $\begin{array}{l}\text { AFIGURA ÇĂO PRAGMLTICA } \\
\text { (A) }\end{array}$ & $\begin{array}{c}\text { SUCASSÃO DE PROFOSIÇŎES } \\
\text { (日) }\end{array}$ \\
\hline $\begin{array}{l}\text { Alvo Ilocuesional } \\
\text { (A1) }\end{array}$ & 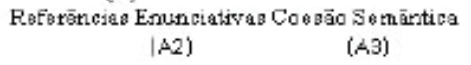 & $\begin{array}{l}\text { Conectisydade Se que ncialidade } \\
\text { (B1) }\end{array}$ \\
\hline
\end{tabular}

Fonte: Adam (1992, p. 21)

Portanto, com fundamento na estrutura prototípica ampliada de Adam (2001), cada proposição argumentativa (P.arg) compreenderá a estrutura do texto como um todo:

P.arg0 - a tese anterior a ser refutada ou confirmada;

P.arg1 - os dados, os fatos do mundo;

P.arg2 - as justificativas que sustentam um posicionamento;

P.arg3 - a conclusão ou posicionamento assumido pelo produtor do texto;

P.arg4 - contra-argumento a uma possível voz contrária.

Dessa forma, a base da estrutura prototípica ampliada de Adam (2001) viabiliza a posição argumentativa das estruturas composicionais do texto, compreendendo as sequências argumentativas prototípicas. Esse, pois, é o ponto de apoio na análise dos textos a serem estudados no córpus deste estudo. 


\section{PROCEDIMENTOS PARA ANÁLISE DO CÓRPUS}

Esta pesquisa tem como córpus as produções textuais realizadas em agosto e setembro de 2017 de uma turma composta por quinze alunos do 3 o ano do Ensino Médio de um colégio estadual da cidade de Goiás, GO.

A constituição do córpus se fez com a parceria do professor da turma, que disponibilizou os textos produzidos pela turma. Assinale-se que a escola segue o regime integral, de modo que os alunos permanecem na instituição o dia todo. Dos trinta textos coletados referentes aos gêneros textuais dissertativoargumentativos, analisa-se somente 15 neste artigo.

Iniciou-se o trabalho de pesquisa com uma revisão bibliográfica sobre a abordagem de sequências textuais prototípicas nos gêneros textuais argumentativos, bem como sobre a fortuna crítica de estudiosos que propõem a construção de suporte teórico-metodológico para subsidiar a produção textual. Posteriormente, efetuou-se um cotejo no córpus, para levantamento das sequências argumentativas prototípicas.

De posse dos dados, procedeu-se à análise e à descrição das sequências textuais prototípicas com fundamento nos postulados da linguística textual. Em seguida, realizou-se também um cotejo da análise resultante da aplicação dos princípios das sequências textuais prototípicas. 
Os procedimentos utilizados para identificar as sequências textuais argumentativas foram: digitalização dos textos para constituição do córpus; processamento dos dados; leituras e análise do córpus; escolha de cinco textos exemplificativos, para a análise detalhada das sequências e suas marcações, visando ao confronto com a teoria de Adam (2001). Como já referido, aplicaram-se procedimentos da pesquisa qualitativa e estudo descritivo específico de uma turma do 30 ano do Ensino Médio de uma Escola Integral na cidade de Goiás. Na sequência, no tópico "Análise dos textos dissertativoargumentativos", apresentam-se, de forma ilustrativa, as sequências argumentativas prototípicas produzidas pelos alunos.

\section{ANÁLISE DOS TEXTOS DISSERTATIVO-ARGUMENTATIVOS}

Os gêneros textuais dissertativo-argumentativo buscam construir uma opinião diante de uma situação-problema, ou seja, uma temática. Refere-se a gêneros que, geralmente, são produzidos no Ensino Médio, com o propósito de aprimorar a capacidade argumentativa dos alunos. Isso porque, nos textos em que a sequência argumentativa se manifesta de modo essencial, é possível construir uma opinião acerca de uma temática polêmica, por meio de argumentos consistentes. Pertencem à ordem do argumentar, 
em que se faz uso de formas usuais para encadear o texto, empregando-se predominantemente o presente como tempo verbal. Constitui-se das seguintes partes: situaçãoproblema, discussão e solução-avaliação. Além disso, devem apresentar unidade temática, objetividade, concretude e questionamento.

A análise dos textos revelou a presença de várias sequências textuais nos textos dos alunos do 30 ano do Ensino Médio, sendo que a estrutura argumentativa prototípica se manifestou de modo essencial.

Segue o que a análise das sequências argumentativas apontou:

\begin{tabular}{|c|c|c|c|c|c|c|c|c|c|c|c|c|c|c|c|c|}
\hline \multicolumn{16}{|c|}{ Protótipo da sequência argumentativa } & \multirow{4}{*}{$\begin{array}{l}\text { Total } \\
15\end{array}$} \\
\hline \multirow[t]{3}{*}{ Qtd } & \multicolumn{3}{|c|}{$\begin{array}{l}\text { Parg.0 } \\
\text { (tese ant.) }\end{array}$} & \multicolumn{3}{|c|}{$\begin{array}{l}\text { Parg.1 } \\
\text { (fatos) }\end{array}$} & \multicolumn{3}{|c|}{$\begin{array}{l}\text { Parg.2 } \\
\text { (justif.) }\end{array}$} & \multicolumn{3}{|c|}{$\begin{array}{l}\text { Parg.3 } \\
\text { (posição) }\end{array}$} & \multicolumn{3}{|c|}{$\begin{array}{l}\text { Parg.4 } \\
\text { (cont.arg.) }\end{array}$} & \\
\hline & S & $\mathbf{R}$ & $\mathbf{N}$ & $\mathbf{S}$ & $\mathbf{R}$ & $\mathbf{N}$ & S & $\mathbf{R}$ & $\mathbf{N}$ & $\mathbf{S}$ & $\mathbf{R}$ & $\mathbf{N}$ & S & $\mathbf{R}$ & $\mathbf{N}$ & \\
\hline & 8 & 4 & 3 & 7 & 3 & 5 & 9 & 5 & 1 & 9 & 4 & 2 & 6 & 7 & 2 & \\
\hline$\%$ & $\begin{array}{l}53,33 \\
\%\end{array}$ & $\begin{array}{l}26,7 \\
6 \%\end{array}$ & $\begin{array}{l}20 \\
\%\end{array}$ & $\begin{array}{l}46, \\
76 \\
\%\end{array}$ & $\begin{array}{l}20 \\
\%\end{array}$ & $\begin{array}{l}33, \\
33 \\
\%\end{array}$ & $\begin{array}{l}60 \\
\%\end{array}$ & $\begin{array}{l}33 \\
, 3 \\
\%\end{array}$ & $\begin{array}{l}6, \\
66 \\
\%\end{array}$ & $\begin{array}{l}60 \\
\%\end{array}$ & $\begin{array}{l}26,7 \\
6 \%\end{array}$ & $\begin{array}{l}13 \\
, 3 \\
3 \\
\%\end{array}$ & $\begin{array}{l}40 \\
\%\end{array}$ & $\begin{array}{l}46,7 \\
\%\end{array}$ & $\begin{array}{l}13,33 \\
\%\end{array}$ & $\begin{array}{l}100 \\
\%\end{array}$ \\
\hline
\end{tabular}

Quadro 1 - Relação geral da ocorrência das proposições argumentativas nos textos do córpus

Esses dados mostram que os alunos estão conseguindo construir sequências argumentativas prototípicas. Em suas produções textuais, os alunos desenvolvem uma tese, utilizam argumentos para sustentar essa tese e apresentam uma proposta de intervenção para a temática preestabelecida. 


\begin{tabular}{|c|c|}
\hline Protótipo da sequência argumentativa & $\begin{array}{l}\text { Textos dos alunos do } 30 \text { ano do Ensino } \\
\text { Médio }\end{array}$ \\
\hline $\begin{array}{l}\text { Tese } \\
\text { anterior } \\
\text { P.ARG } 0\end{array}$ & $\begin{array}{l}\text { No Brasil o numero de menores infratores } \\
\text { estão aumentando. }\end{array}$ \\
\hline $\begin{array}{l}\text { Dados } \\
\text { Premissas } \\
\text { P.ARG } 1\end{array}$ & $\begin{array}{l}\text { por causa que os traficantes estão usando } \\
\text { esses menores para venderem suas drogas } \\
\text { e roubar para eles por causa que quando } \\
\text { eles, são pegos pelo policia são liberados } \\
\text { por não ter idade para ir a cadeia. }\end{array}$ \\
\hline $\begin{array}{l}\text { Escoramento de referências } \\
\text { Suporte argumentativo } \\
\text { P.ARG } 2\end{array}$ & $\begin{array}{l}\text { Mas estava em discução a redução da } \\
\text { maior idade penal de dezoito para dezeseis } \\
\text { isso fez; que as pessoas pensassem a } \\
\text { atitude desses menores infratores, }\end{array}$ \\
\hline $\begin{array}{l}\text { Especificação contra-argumento } \\
\text { P.ARG } 3\end{array}$ & $\begin{array}{l}\text { não forem muitas as pessoas que gostaram } \\
\text { disso redução, a maioria aprovaram, } \\
\text { porque essas pessoas estava cansadas de } \\
\text { serem roubadas por essas crianças que } \\
\text { deveriam estar nas escolas estudando } \\
\text { para ter um futuro melhor. Essa lei foi um } \\
\text { alerta para esses ladrões para entimidar e } \\
\text { tentar diminuir o índice de roubo e morte } \\
\text { mais esse projeto foi uma ótima maneira } \\
\text { de punir esses menores }\end{array}$ \\
\hline $\begin{array}{l}\text { Conclusão } \\
\text { Nova tese } \\
\text { P.ARG } 4\end{array}$ & $\begin{array}{l}\text { por que quem sofre são os moradores e a } \\
\text { população por sentir medo de sair nas ruas } \\
\text { por serem assaltado quase todo os dias, } \\
\text { sera que o Brasil existe uma salvação para } \\
\text { sair dessa violencia que o Brasil por que a } \\
\text { violencia e o crime não compensa. }\end{array}$ \\
\hline
\end{tabular}

Quadro 2 - Texto 1

Ainda vale completar que, para Adam (2008), como apontado anteriormente, um texto constitui-se de uma estrutura hierárquica que pode compreender sequências de mesmo tipo ou de tipos diferentes.

\section{CONSIDERAÇÕES FINAIS}

\section{Este texto tratou das sequências argumentativas} prototípicas presentes nos textos dissertativo-argumentativos 
produzidos por alunos do 3 ano do Ensino Médio. Mais especificamente, descreveu-se como as sequências textuais argumentativas prototípicas dos textos estão organizadas, seguindo o modelo de Adam (2008).

Com esta investigação em curso, objetiva-se preencher lacunas existentes, sobretudo no estudo dos gêneros textuais argumentativos, e apontar caminhos teórico-metodológicos para o ensino de produção textual na educação básica.

Sabe-se que as sequências textuais argumentativas buscam construir uma opinião de modo progressivo. Para isso, "o enunciador vale-se de uma argumentação coerente e consistente: expõe os fatos, reflete a respeito de uma questão, tece explicações, apresenta justificativas, avalia, conceitua e exemplifica" (KÖCHE; BOFF; MARINELLO, 2010, p.22)

Ao analisar os textos produzidos pelos alunos que estão concluindo a educação básica, evidenciou-se que embora esses sujeitos apresentem dificuldades na utilização da língua portuguesa, eles conseguem produzir textos dissertativoargumentativos, ou seja, que objetivam persuadir e convencer o interlocutor em uma interação verbal. Os textos analisados apresentam as macroposições das sequências argumentativas: tese anterior, fatos, inferências, construção de argumentos e conclusão (nova tese). 


\section{REFERÊNCIAS}

ADAM, Jean-Michel (2001). Les textes: types et prototypes - récit, description, argumentation, explication et dialogue. Paris: Natan.

ADAM, Jean-Michel (2008). A linguística textual: introdução à análise dos discursos. São Paulo: Cortez.

BAKHTIN, Mikhail (2010 [1992]). Estética da criação verbal. São Paulo: Martins Fontes.

BEZERRA, Benedito Gomes; RODRIGUES-BIASE, Bernardete; CAVALCANTE, Magalhães Mônica (Org.) (2009). Gêneros e sequências textuais. Recife: Edupe.

BAZERMAN, Charles (1994). Constructing experience. Carbonde, IL: Southern Illinois University Press.

BONINI, Adair; MEURER, José Luiz; MOTTA-ROTH, Désirée (Org.) (2005). Gêneros: teorias, métodos, debates. São Paulo: Parábola.

BRAIT, Beth (2000). "Gêneros e ensino de língua: faces discursivas da textualidade". In: ROJO, Roxane Helena Rodrigues (Org.). Praticando os PCNs: dos Parâmetros Curriculares Nacionais à Prática de Sala de Aula (Língua Portuguesa). 1.ed. São Paulo: Mercado Aberto/Educ.

BRASIL (2000). Parâmetros Curriculares Nacionais: Ensino Médio. Brasília, DF: Ministério da Educação, Secretaria de Educação Média e Tecnológica. BRASIL (2002). PCN+ Ensino Médio: Orientações Educacionais Complementares aos Parâmetros Curriculares Nacionais. Brasília, DF: Ministério da Educação, Secretaria de Educação Média e Tecnológica.

KÖCHE, Vanilda Salton; BOFF, Odete Maria Benetti; MARINELLO, Adriane Fogali (2010). Leitura e produção textual: gêneros textuais do argumentar e expor. Petrópolis, RJ: Vozes.

MARCUSCHI, Luiz Antônio (2002). "Gêneros textuais: definição e funcionalidade". In Gêneros textuais: constituição e práticas sociodiscursivas. São Paulo: Cortez.

MARCUSCHI, Luiz Antônio (2008). Produção textual, análise de gêneros e compreensão. São Paulo: Parábola. 
MOTTA-ROTH, Désirée; HEBERLE, Viviane M (2005). "O conceito de "estrutura potencial do gênero" de Rusqayia Hasan". In: MEURER, José Luiz; BONINI, A.; MOTTA-ROTH, Désirée (Orgs.). Gêneros: teorias, métodos e debates. 1.ed. São Paulo: Parábola Editorial.

RODRIGUES, Rosangela Hamives (2005). “Os gêneros do discurso na perspectiva dialógica da linguagem: a abordagem de Bakhtin". In: MEURER, José Luiz; BONINI, Adair; MOTTA-ROTH, Désirée (Orgs.). Gêneros: teorias, métodos, debates. São Paulo: Parábola.

ROJO, Roxane (2005). "Gêneros do discurso e gêneros textuais: questões teóricas e aplicadas". In: MEURER, José Luiz; BONINI, Adair; MOTTA-ROTH, Désirée (Org.). Gêneros: teorias, métodos, debates. São Paulo: Parábola.

Eleone Ferraz de Assis é pós-doutor em Estudos Linguísticos (UFG) e doutor em Língua Portuguesa (UERJ). Professor adjunto da Universidade Estadual de Goiás. Coordenador do Programa de Pós-Graduação em Língua, Literatura e Interculturalidade dessa instituição. É autor do livro Iconicidade Lexical: o insólito em Sombras de Reis Barbudos (Dialogarts/UERJ, 2017) e organizador do livro Caminhos para a Educação Linguística (Pontes, 2017). Pesquisador do Grupo de Pesquisa Diretório CNPQ Semiótica, Leitura e Produção de Textos - SELEPROT. E-mail: leo.seleprot@gmail.com

Fernanda Martins da Costa Gomes é aluna do Programa de Pós-Graduação em Língua, Literatura e Interculturalidade. Graduada em Letras e Pósgraduada em Língua Portuguesa: Texto, Discurso e Ensino pela mesma instituição. Professora de cursos técnicos da Secretaria Estadual de Ciência e Tecnologia de Goiás. 